\title{
Genetic dissection of grain architecture- related traits in a winter wheat population
}

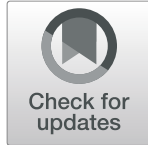

Matías Schierenbeck ${ }^{1,2,3^{*}}$, Ahmad M. Alqudah ${ }^{4 *}$, Ulrike Lohwasser ${ }^{1}$, Rasha A. Tarawneh ${ }^{1}$, María Rosa Simón ${ }^{2,3}$ and Andreas Börner ${ }^{1}$

\begin{abstract}
Background: The future productivity of wheat (T. aestivum L.) as the most grown crop worldwide is of utmost importance for global food security. Thousand kernel weight (TKW) in wheat is closely associated with grain architecture-related traits, e.g. kernel length $(K L)$, kernel width (KW), kernel area (KA), kernel diameter ratio (KDR), and factor form density (FFD). Discovering the genetic architecture of natural variation in these traits, identifying QTL and candidate genes are the main aims of this study. Therefore, grain architecture-related traits in 261 worldwide winter accessions over three field-year experiments were evaluated.

Results: Genome-wide association analysis using 90K SNP array in FarmCPU model revealed several interesting genomic regions including 17 significant SNPs passing false discovery rate threshold and strongly associated with the studied traits. Four of associated SNPs were physically located inside candidate genes within LD interval e.g. BobWhite_c5872_589 (602,710,399 bp) found to be inside TraesCS6A01G383800 (602,699,767-602,711,726 bp). Further analysis reveals the four novel candidate genes potentially involved in more than one grain architecturerelated traits with a pleiotropic effects e.g. TraesCS6A01G383800 gene on 6A encoding oxidoreductase activity was associated with TKW and KA. The allelic variation at the associated SNPs showed significant differences betweeen the accessions carying the wild and mutated alleles e.g. accessions carying C allele of BobWhite_c5872_589, TraesCS6A01G383800 had significantly higher TKW than the accessions carying T allele. Interestingly, these genes were highly expressed in the grain-tissues, demonstrating their pivotal role in controlling the grain architecture.

Conclusions: These results are valuable for identifying regions associated with kernel weight and dimensions and potentially help breeders in improving kernel weight and architecture-related traits in order to increase wheat yield potential and end-use quality.
\end{abstract}

Keywords: Thousand kernel weight, Winter wheat, GWAS, Grain architecture, Candidate genes

\section{Background}

Meeting the globally increasing demand for wheat ( $T$. aestivum L.), the main source of protein and calories in human food is a major aim to ensure global food

\footnotetext{
* Correspondence: m_schierenbeck@hotmail.com;

mschierenbeck@conicet.gov.ar; ama@agro.au.dk; ahqudah@gmail.com ${ }^{1}$ Genebank Department, Leibniz Institute of Plant Genetics and Crop Plant Research (IPK), OT Gatersleben, Corrensstr 3, D-06466 Seeland, Germany ${ }^{4}$ Department of Agroecology, Aarhus University at Flakkebjerg, Forsøgsvej 1, 4200 Slagelse, Denmark

Full list of author information is available at the end of the article
}

security. By 2050, the world population will reach 9800 billion and the annual rate of food demand will reach $1.6 \%$ surpassing the current annual genetic gains of this crop [1].

The increase in grain yield had been based mainly on the increase in the number of grains per area $[2,3]$, whereas some other traits as thousand-grain weight (TKW) remained unchanged [4]. However, increasing grain yield and its potential could be reached through improving grain architecture-related-traits which helps in boosting TKW $[5,6]$.

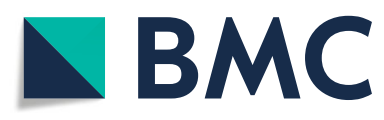

(c) The Author(s). 2021, corrected publication 2021. Open Access This article is licensed under a Creative Commons Attribution 4.0 International License, which permits use, sharing, adaptation, distribution and reproduction in any medium or format, as long as you give appropriate credit to the original author(s) and the source, provide a link to the Creative Commons licence, and indicate if changes were made. The images or other third party material in this article are included in the article's Creative Commons licence, unless indicated otherwise in a credit line to the material. If material is not included in the article's Creative Commons licence and your intended use is not permitted by statutory regulation or exceeds the permitted use, you will need to obtain permission directly from the copyright holder. To view a copy of this licence, visit http://creativecommons.org/ licenses/by/4.0/. The Creative Commons Public Domain Dedication waiver (http://creativecommons.org/publicdomain/zero/1. 0/) applies to the data made available in this article, unless otherwise stated in a credit line to the data. 
Although the trade-off between the grain number and TKW is well known [7-9], no differences in TKW have been found in some genotypes with a high spikelet number [10] indicating that a high TKW can be achieved keeping the grain number unmodified and potentially increasing grain yield. This suggests that selection for heavier grains could be highly effective for improving wheat yields [11]. Therefore, understanding the genetic basis of grain architecture related-traits is important to accelerate the genetic gain of wheat grain yield. Nevertheless, TKW and kernel size are complex genetic traits controlled by multiple loci/genes with the influnce of environmental cues and genotype $\times$ environment $(G \times E)$ interactions $[12,13]$.

Kernel weight contributes about $20 \%$ of the genetic variation in grain yield. Besides that, kernel weight is a stable, heritable character, thus suitable to select in segregating generations in plant breeding [14]. Furthermore, TKW was also reported to increase seedling vigor and germination [15]. A higher TKW also generates a higher flour yield $[16,17]$. In durum wheat, TKW, kernel volume and test weight are also associated with semolina yield [18].

Grain architecture-related traits can also be associated with milling and processing wheat quality $[19,20]$. A close phenotypic association between TKW with other kernel size traits such as kernel length (KL), kernel width (KW), and kernel diameter ratio (KDR) in bread wheat has been recognized [15] and those traits have been reported as modifying milling quality [21]. It has been indicated that grain characteristics are important attributes for determining the market value of wheat grain since they influence the specific weight and milling performance. Moreover, Evers et al. [22] reported that large and spherical grains optimize grain morphology increasing milling efficiency. For their part, Millar et al. [23] described that kernel size was associated with various characteristics of flour, such as protein content and hydrolytic enzymes activity that are closely related to baking quality and end-use suitability whereas Morgan et al. [24] reported the association of kernel size with flour-water dough quality. Despite this, the phenotypic and genetic variation of grain morphology is surprisingly understudied compared to other grain yield components, mainly due to the difficulty in quantifying this trait [25-28].

Exploration of crop genetic resources is useful to recognize sources of variation for agronomic and physiological traits and discovery of new alleles for improving yield potential, their components as well as grain quality traits [11, 29, 30]. Moreover, quantitative trait loci (QTL) mapping is a key approach to understand the genetic architecture of kernel traits. This tool has been implemented in several crops and generates important progress in identifying major QTL and isolating underlying genes for grain weight and size in rice, maize, and barley [31-33]. For bread wheat, several QTL associated with kernel morphology have been reported in recombinant inbred lines (RIL) populations such as qTKW-1A.1, qTKW-2D.4 and QTkw.ncl-5B.2 on chromosomes $1 \mathrm{~A}, 2 \mathrm{D}$ and $5 \mathrm{~B}$, respectively $[20,21,32,34$, 35], doubled-haploid (DH) populations like Xgwm234, XwPt0052 and XwPt9824 on chromosomes 5B, 6B and $7 \mathrm{~A}$, respectively $[15,21,36-38]$ and $\mathrm{F}_{2}$ populations containing synthetic hexaploid wheat lines such as Xcfd282-Xbarc62, Xhbe341-Xbarc225 and Xhbd166Xcfd81 on chromosomes 1D, 4D and 5D, respectively [39]. Genome-wide association scan (GWAS) has been used to detect several genomic regions and candidate genes underlying the natural variation of TKW and other grain yield components [9, 11, 14, 25, 40-43]. Up to now, QTL associated with grain architecture traits in winter wheat have been reported (e.g., $A X \_111147652$ on 1B; $A X \_110046841$ on 4A; $A X \_110713957$ on 4B; AX_110958315 on 5A; IWB50649 on 5B) but new efforts are required exploring different environments and germplasm from different origins in order to enhance grain yield and quality.

In addition, most of what is known about genetic control of TKW had been carried out using biparental populations which present some limitations $[34,38,44]$. Several candidate genes have been associated with TKW and related traits QTLs [14, 41, 42]. For example, a pseudo-response regulator $(P p d-A 1)$ at 2A (TRITD2Av1G019250), TRITD4Bv1G171270 at 4B encoding a Big Grain 1 protein, and two other candidate genes at 6B (TRITD6Bv1G005370 and TRITD6Bv1G005450) encoding an acid $\beta$ fructofuranosidase have been detected within QTL for $\mathrm{KL}$ and TKW in recombinant inbred lines (RILs) population [45]. Interestingly, QTL for KA with candidate genes involved in auxin were detected, for instance, TRITD1Bv1G118820, TRITD2Av1G189400 and TRITD7Bv1G173200 encoding auxin response while TRITD4Bv1G175480 involved in auxin signaling and TRITD3Av1G012070, encoding for a Flavin-containing monooxygenase as an auxin biosynthesis. Moreover, candidate genes encoding for cytochrome P450 were found in most of the TKW QTL [45].

Other candidate genes as TraesCS4A02G229100 which is an auxin-regulated gene involved in organ size and TraesCS4A02G2 corresponding to a polygalacturonase involved in carbohydrate metabolic process increasing kernel size and TKW [43] were found on chromosome 4AL. However, associations varied according to the environments and genotypes, indicating that new studies in different environments and germplasm should be carried out. 
Therefore, to gain deeper insights into the genetic basis of grain architecture-related-traits that could be of interest for the future improvement of grain yield and quality, a GWAS was undertaken in a diverse winter wheat panel of 261 genotypes tested during 3 years. For this purpose, 17,093 SNPs markers with recently known physical position were used to detect the most significant and effective SNP and for the identification of candidate genes underlying the studied traits. Our results showed 17 highly associated SNPs across 9 chromosomes of which four multi-traits associated SNPs were reported on chromosomes $1 \mathrm{~B}, 2 \mathrm{~A}, 5 \mathrm{~B}$, and $6 \mathrm{~A}$. These SNPs were located within the physical positions of candidate genes which are potentially associated with grain architecture-related traits and potentially involved in improving grain weight and size.

\section{Results}

\section{Population structure and SNP coverage}

The markers were distributed within the whole genome. The highest coverage of markers $(51.5 \%)$ was on genome B with 8809 SNPs, genome A was covered by $38.6 \%$ of the whole markers with 6595 SNPs, while D genome presented the lowest coverage, 9.9\% (1689 SNPs). The homoeologous group 1 chromosome had the highest number of SNPs (17.96\%), while the chromosomes of group 4 presented only $7.02 \%$. Chromosome 5B harboured the highest number of SNPs with 1784 markers, while chromosome 4D held only 46 SNPs (Supplementary Fig. S2).

Based on the PCA, the panel clustered in three groups strongly according to their different origins: 66 genotypes from Central-Northern Europe (25.2\%), 146 genotypes from Eastern Europe-Western Asia (55.6\%), and 42 North-American accessions (16\%) (Table S1; Supplementary Fig. S3). Heatmaps kinship matrix with dendrograms confirmed that there are clusters among the accessions based on the used SNPs (Supplementary Fig. $\mathrm{S} 4)$. The mean $\mathrm{r}^{2}$ values for the whole wheat genome decreased with increasing distance between SNPs as Mbp.
The average LD decay distance for the whole genome was approximately 2 Mbp (Supplementary Fig. S5).

\section{Variation in seed size-related traits and correlations}

Data analysis revealed extensive phenotypic variation in all studied traits suggesting the suitability of the used panel for association genetic studies. Phenotypic values for each of the six traits were found normally distributed. All variables analyzed were significantly influenced by the years, genotypes, and $G \times Y$ (environment) interactions $(p<0.001)$ (Table 1$)$. Broad-sense heritability was high ranging from 0.87 (Factor form density) to 0.93 (Kernel length). The main results and summary statistics are indicated in Table S2.

For TKW, BLUEs values across the three field environments (years) varied from 31.06 to $60.16 \mathrm{~g}$, showing ranges of 29.08 to $61.11 \mathrm{~g}$ (2016), 31.15 to $60.37 \mathrm{~g}$ (2017), and 31.04 to $63.05 \mathrm{~g}$ (2018) as shown in Table S2 and Fig. 1. The KL means ranged from 5.60 to $7.54 \mathrm{~mm}$. Values ranged from 5.57 to $7.70 \mathrm{~mm}$ (2016), 5.62 to 7.60 $\mathrm{mm}$ (2017), and 5.54 to $7.44 \mathrm{~mm}$ in 2018. Kernel width (KW) varied from 3.10 to $4.06 \mathrm{~mm} \mathrm{(2016);} 3.06$ to

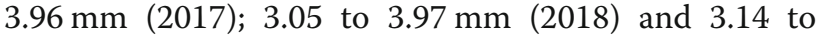
$3.88 \mathrm{~mm}$ (BLUEs). Variations in KA fluctuated between $\quad 13.05-22.23 \mathrm{~mm}^{2} \quad$ (2016), $13.10-21.92 \mathrm{~mm}^{2}$ (2017), $12.81-21.75 \mathrm{~mm}^{2}$ (2018) and $13.26-21.52 \mathrm{~mm}^{2}$ (BLUEs). KDR ranged from 1.58 to 2.15 (2016); 1.60 to 2.15 (2017); 1.58 to 2.07 (2018) and 1.59 to 2.11 (BLUEs). BLUEs values for FFD ranged from 1.66 to 2.13. FFD varied between 1.58-2.12 (2016), 1.63-2.12 (2017) and 1.66-2.13 (2018) (Table S2; Fig. 1; Supplementary Fig. S6). Boxplots showing natural phenotypic variation among genotypes across years are indicated in Fig. 1. The evaluated traits showed high heritability $(>0.87)$ over the 3 years, indicating that most of the traits were stable and largely determined by genetic factors (Table 1 Supplementary Fig. S6).

TKW showed significant $(P<0.001)$ and positive correlation with KA (0.91), KW (0.82), KL (0.78), FFD (0.68) and a weaker association with KDR (0.13). The KA revealed a strong correlation with KL (0.90), KW

Table $1 P$ values and broad sense heritability of Thousand-kernel weight (TKW), Kernel length (KL), Kernel width (KW), Kernel area $(K A)$, Kernel diameter ratio (KDR) and Factor form density (FFD) in an experiment with 261 wheat genotypes evaluated during three years

\begin{tabular}{|c|c|c|c|c|}
\hline Trait & Year & Genotype & GenotypexYear & $H^{2}$ \\
\hline Thousand kernel weight (TKW) & $* * *$ & $* * *$ & $* * *$ & 0.90 \\
\hline Kernel length (KL) & $* * *$ & $* * *$ & $* * *$ & 0.93 \\
\hline Kernel width (KW) & $* * *$ & $* * *$ & $* * *$ & 0.88 \\
\hline Kernel area (KA) & $* * *$ & $* * *$ & $* * *$ & 0.90 \\
\hline Kernel diameter ratio (KDR) & $* * *$ & $* * *$ & $* * *$ & 0.92 \\
\hline Factor form density (FFD) & $* * *$ & $* * *$ & $* * *$ & 0.87 \\
\hline
\end{tabular}

$\mathrm{H}^{2}$ : broad-sense heritability. ${ }^{* *}$ indicate significance $P<0.001$ 


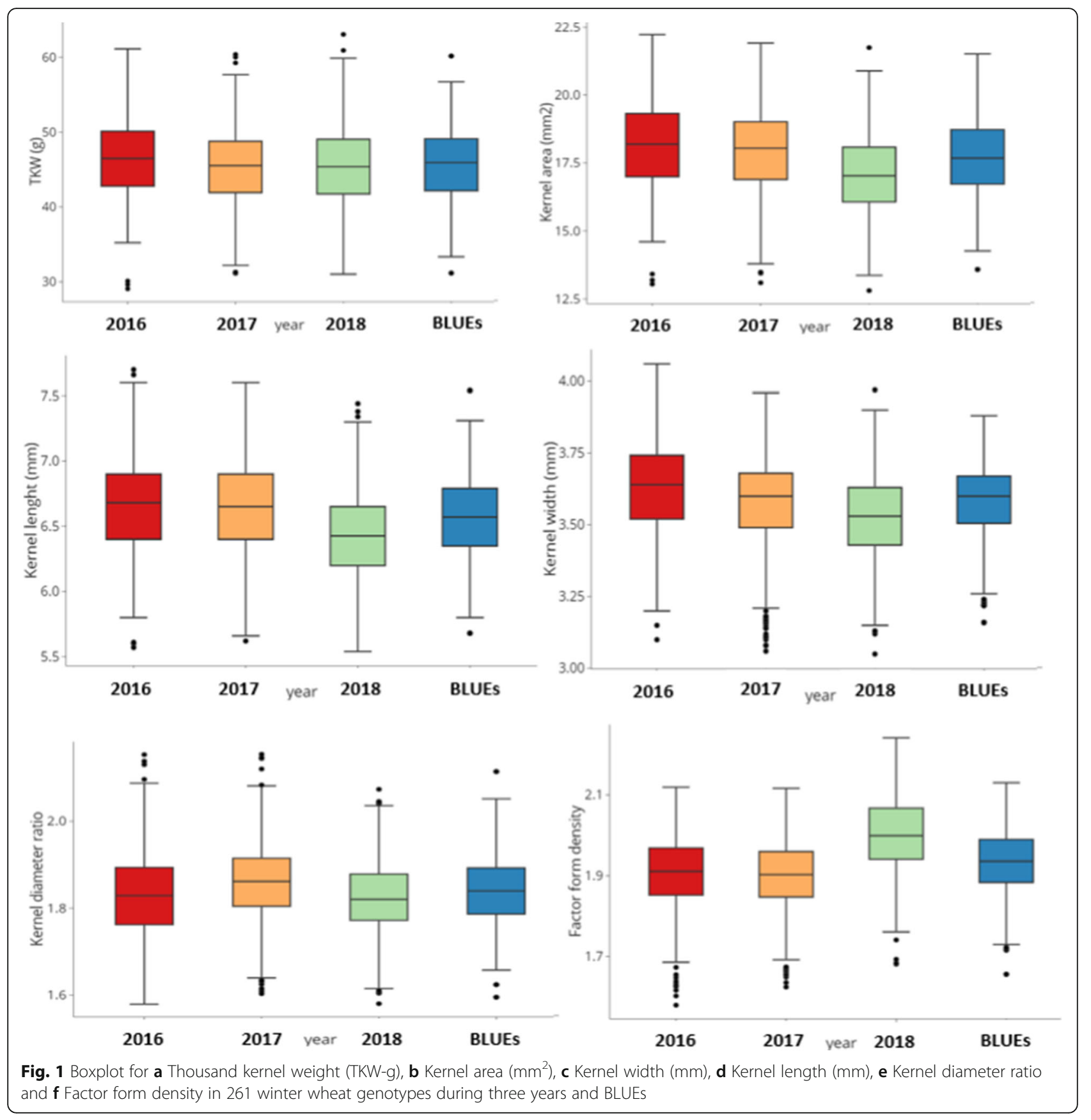

(0.84) while weaker associations were detected for KDR (0.24) and FFD (0.33). The KL and KW presented a positive correlation (0.55), while a negative association was reported for KW and KDR $(-0.31)$ and KDR with FFD $(-0.14)$ (Fig. 2). The correlation values suggesting that common genetic factors controlling more than two traits are expected to be detected in the current study.

Important differences in these traits were detected when the different origins of the genotypes were contrasted. In this sense, those cultivars from East EuropeWestern Asia (e.g., Russia, Kazakhstan, Kirgizstan,
Ukraine) presented higher TKW $(48.18 \mathrm{~g})$ and KA $\left(18.28 \mathrm{~mm}^{2}\right)$ compared to those from Central and Northern Europe $\left(45.36 \mathrm{~g} ; 17.81 \mathrm{~mm}^{2}\right.$ ) (France, Poland, Germany, UK, Romania, Sweden, Finland, etc.) and North America which presented the lowest values (41.41 g; $16.32 \mathrm{~mm}^{2}$ ) (Supplementary Fig. S7).

\section{Candidate genes underlying grain architecture-related} traits in wheat

The highly significant SNP markers which passed the FDR threshold and associated with more than one trait 


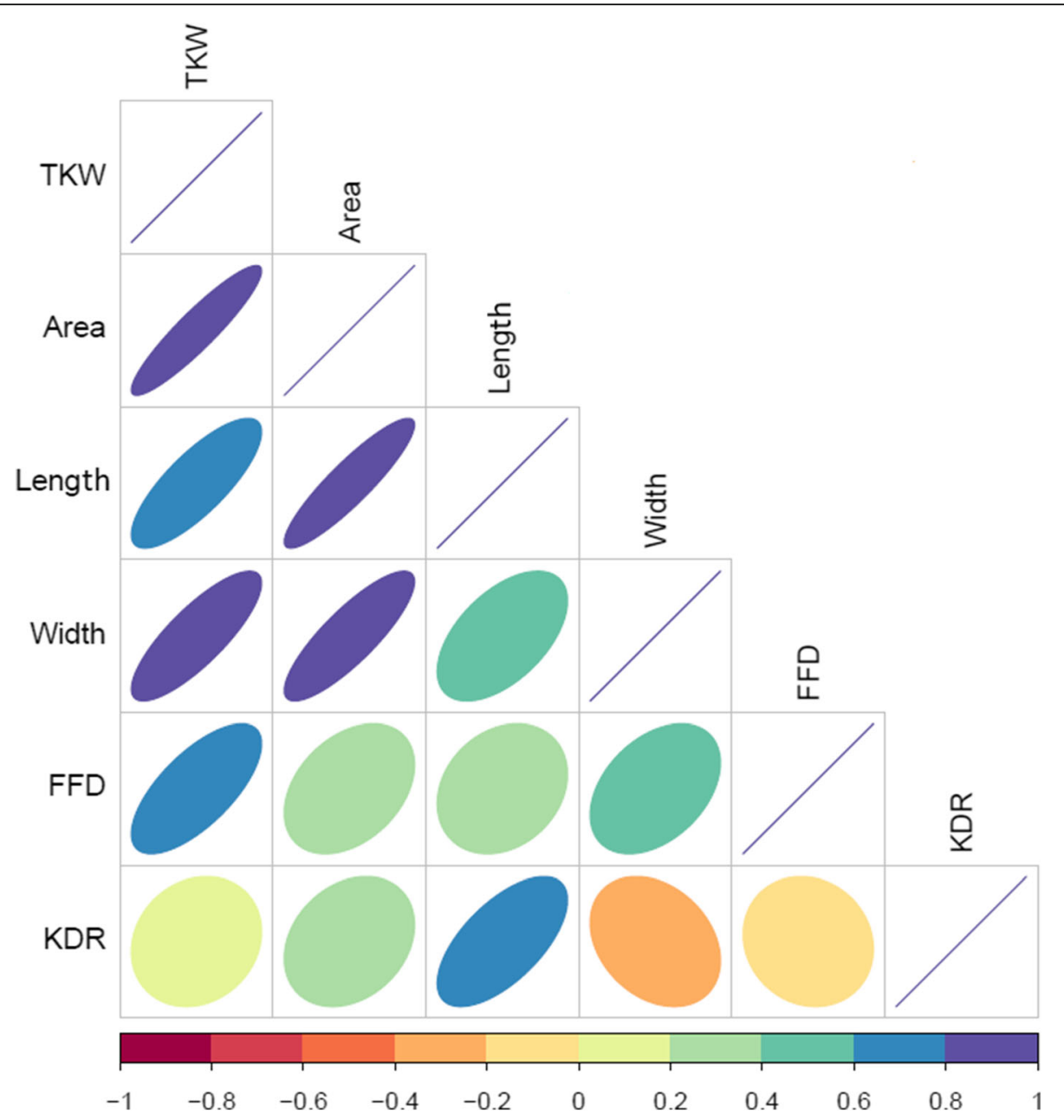

Fig. 2 Pearson Correlation Coefficient values in wheat genotypes based on BLUEs value. The degree of significance for all correlations was $p<$ 0.001. The color and size of the ellipse reflect the strength of the correlation

were selected for detecting putative candidate genes. One hundred forty-nine high confidence candidate genes were fallen within the LD interval (2Mbp) (Table 2; Table S4). Some of these genes were found to encode proteins with known functions, however, other genes showed unknown functions. Four SNPs were found to be inside the physical position of four novel candidate genes those were selected according to their annotation and association with several grain architecture traits.

The candidate gene TraesCS1B01G303200 on chromosome 1B (position 524,153,507-524,155,132 bp) was annotated as a protein of unknown function DUF1677 in rice $(O$. sativa). The candidate gene TraesCS2A01G136800 is located on chromosome 2A (position $82,349,905-82,354,821 \mathrm{bp}$ ) and has a role in Heat shock protein DnaJ, cysteine-rich domain. The alleles of SNP Excalibur_c12169_1088 (position 82,350,252-82,350,352 bp) which is located within the interval of the previous candidate gene did not show a significant effect on the associated traits as shown in Fig. 4. On chromosome 5B,
SNP RAC875_c9150_2945 (position 459,477,406$459,477,506 \mathrm{bp}$ ) is co-located within the candidate gene TraesCS5B01G274000 (position 459,476,178$459,493,013 \mathrm{bp}$ ); the carrying alleles are $\mathrm{C}$ and $\mathrm{T}$ where allele $\mathrm{C}$ affect significantly KA and KL $(p<0.05)$ (Fig. 4). The candidate gene annotates P-loop containing nucleoside triphosphate hydrolase. The last identified candidate gene TraesCS6A01G383800 is located on chromosome 6A (position 602,699,767-602,711,726 bp) and encodes an oxidoreductase activity, acting on a sulfur group of donors, $\mathrm{NAD}(\mathrm{P})$ as acceptor. The SNP BobWhite_c5872_589 located within the gene (position 602,710,319-602,710,419 bp) held $C$ and $T$ alleles, where allele $\mathrm{C}$ affected TKW significantly $(p<0.01)$ but had no significant effect on KA.

The expression analysis of candidate genes in different grain tissues showed a wide range of expression for the genes (Fig. 5). In general terms, gene TraesCS6A01G383800 shows the highest expression in most of the grain tissues (grain, aleurone layer, starchy 
Table 2 Distribution of pleiotropic loci associated with two or more grain architecture related traits

\begin{tabular}{|c|c|c|c|c|c|}
\hline$\overline{C h r}$ & Marker & $\begin{array}{l}\text { Trait/Effect/ } \\
-\log _{10}(p- \\
\text { value })\end{array}$ & $\begin{array}{l}\text { Marker } \\
\text { Position (bp) } \\
\text { and alelles }\end{array}$ & $\begin{array}{l}\text { Candidate gene- } \\
\text { Genomic location }\end{array}$ & Annotation \\
\hline $1 \mathrm{~B}$ & $\begin{array}{l}\text { wsnp_Ex } \\
\text { c1600_3051075 } \\
\text { (IWA2084) }\end{array}$ & $\begin{array}{l}\text { TKW }(+ \\
1.611) 4.20 \\
\text { KA (+0.134) } \\
5.66\end{array}$ & $\begin{array}{l}524,154,547- \\
524,154,747 \\
\text { T-G }\end{array}$ & $\begin{array}{l}\text { TraesCS1B01G303200 } \\
(524153507- \\
524,155,132)\end{array}$ & Protein of unknown function DUF1677, 0 . sativa \\
\hline $2 \mathrm{~A}$ & $\begin{array}{l}\text { Excalibur } \\
\text { c12169_1088 } \\
\text { (IWB22047) }\end{array}$ & $\begin{array}{l}\text { TKW }(+ \\
2.176) 6.91 \\
\text { KA }(+0.576) \\
5.76\end{array}$ & $\begin{array}{l}82,350,252- \\
82,350,352 \\
A-G\end{array}$ & $\begin{array}{l}\text { TraesCS2A01G136800 } \\
(82349905- \\
82,354,821)\end{array}$ & $\begin{array}{l}\text { Heat shock protein binding (Gos) } \\
\text { Heat shock protein DnaJ, cysteine-rich domain (interpros) }\end{array}$ \\
\hline $5 B$ & $\begin{array}{l}\text { RAC875_c9150_ } \\
2945 \\
\text { (IWB61034) }\end{array}$ & $\begin{array}{l}\mathrm{KA}(-0.318) \\
5.23 \\
\mathrm{KL}(-0.110) \\
4.20\end{array}$ & $\begin{array}{l}459,477,406- \\
459,477,506 \\
\text { C-T }\end{array}$ & $\begin{array}{l}\text { TraesCS5B01G274000 } \\
(459476178- \\
459,493,013)\end{array}$ & $\begin{array}{l}\text { P-loop containing nucleoside triphosphate hydrolase } \\
\text { (interpros) }\end{array}$ \\
\hline $6 \mathrm{~A}$ & $\begin{array}{l}\text { BobWhite } \\
\text { c5872_589 } \\
\text { (IWB4014) }\end{array}$ & $\begin{array}{l}\text { TKW } \\
(-1.755) \\
6.34 \\
\text { KA }(-0.516) \\
5.70\end{array}$ & $\begin{array}{l}602,710,319- \\
602,710,419 \\
\text { C-T }\end{array}$ & $\begin{array}{l}\text { TraesCS6A01G383800 } \\
(602699767- \\
602,711,726)\end{array}$ & $\begin{array}{l}\text { Oxidation-reduction process/MF: oxidoreductase activity/MF: } \\
\text { NADP binding/MF: oxidoreductase activity, acting on a sulfur } \\
\text { group of donors, NAD(P) as acceptor/BP: cell redox } \\
\text { homeostasis/MF: flavin adenine dinucleotide binding/MF: } \\
\text { glutathione-disulfide reductase activity/BP: glutathione meta- } \\
\text { bolic process }\end{array}$ \\
\hline
\end{tabular}

TKW Thousand-kernel weight, KL Kernel length and KA Kernel area, Chr Chromosome, Position (Physical, bp); - $\log _{10}(p$-value (SNP))

endosperm and the seed coat, endosperm, grain transfer cells, and whole endosperm) while genes TraesCS1B01G303200 and TraesCS2A01G136800 also showed high values. For their part, TraesCS5B01G274000 gene had very low expression compared with the other three but showed high expression values for embryo proper (Fig. 5).

Interestingly in Chromosome 1A, the SNP TA0012860611-w showed a significant association with TKW and a weaker association with $\mathrm{KA}(\mathrm{LOD}=3.18)$. This region harbors the candidate gene TraesCS1A01G007200 (position 3,776,265-3,777,399 bp) which annotates Gliadin/ LMW glutenin/Bifunctional inhibitor/plant lipid transfer protein/seed storage helical domain (Table S3). The analysis of SNP allele variation in marker TA001286-0611w (position 3,777,195-3,777,321 bp) showed that allele C has a significant impact on TKW $(p<0.01)$ but had no effect on KA compared to allele $\mathrm{T}$ (Data not shown).

\section{GWAS results}

In total, 17 MTAs across 9 chromosomes related to grain architecture related-traits were detected above the false discovery rate (FDR) threshold $\left(-\log _{10}>\right.$ FDR). FDR threshold was above than $-\log _{10}>4.2$ for the studied traits. Therefore, we reduced the number of spurious associations by only considering those SNPs, which exceeded the FDR. Markers were identified on chromosomes 1A (1), 1B (2), 2A (2), 2B (3), 3A (1), 4B (1), 5B (4), 6A (2), 6B (1) (Fig. 3, Supplementary Fig. S8 and Table S3).

For TKW, seven MTAs were identified and present on chromosomes 1A (1), 2A (1), 2B (2), 6A (1) and 6B (1). Four of these markers located on chromosomes $2 \mathrm{~A}, 2 \mathrm{~B}$,
$6 \mathrm{~A}$, and 6B showed highly significant associations $\left(-\log _{10}>5\right)$. The most significant marker $\left(-\log _{10}=6.91\right)$ was Excalibur_c12169_1088 located in chromosome 2A and affected this trait by $+2.176 \mathrm{~g}\left(\mathrm{R}^{2}=5.2 \%\right)$. The phenotypic variation explained by markers $\left(R^{2}\right)$ ranged between 3.2 to $5.2 \%$ (Supplementary Table S3).

For kernel area, seven MTAs on chromosomes 1B (1), $2 \mathrm{~A}(1), 2 \mathrm{~B}(1), 3 \mathrm{~A}(1), 4 \mathrm{~B}(1), 5 \mathrm{~B}(1)$ and $6 \mathrm{~A}(1)$ were reported. Six of these MTAs located on 1B, 2A, 2B, 3A, 5B and $6 \mathrm{~A}$ showed $-\log _{10}>5$. For this trait, markers Tdurum_contig59780_988 located on chromosome 2B $\left(-\log _{10}=6.88\right.$, Effect $\left.=-0.408 \mathrm{~mm}^{2}, \mathrm{R}^{2}=2.8 \%\right)$, Excali bur_c12169_1088 on chromosome 2A $\left(-\log _{10}=5.76\right.$, Effect $\left.=+0.576 \mathrm{~mm}^{2} ; \quad \mathrm{R}^{2}=1.9 \%\right)$ and wsnp_Ex_c1600_ 3051075 on chromosome $1 \mathrm{~B}\left(-\log _{10}=5.66\right.$, Effect $=+$ $\left.0.605 \mathrm{~mm}^{2}, \mathrm{R}^{2}=1.9 \%\right)$ were the most significant ones detected. Marker effects oscillated between 1.9 to 2.6\% (Supplementary Table S3).

Three MTAs related to kernel length were detected on chromosome5B (RAC875_c9150_2945, Excalibur_ c23709_938 and Kukri_c10530_1013) that showed high effects in these traits. $\mathrm{R}^{\overline{2}}$ reached values of 2.0 to $2.2 \%$.

No MTAs were detected for FFD, KDR and KL when the $-\log 10>$ FDR threshold was used. Conversely, several MTAs were reported between the $-\log 10>3$ and - $\log 10<$ FDR range: 5 (KA), 2 (FFD), 19 (KDR), 3 (KA), 1 (TKW), $23(\mathrm{KL})$. Information about SNP detected for each trait, their physical position, $-\log _{10}$, MAF, effect, related candidate genes, and their functions are shown in Supplementary Table S3.

For all of these markers associated with the studied traits, we detected the closest candidate genes based on the physical position within local blocks of LD. Our 


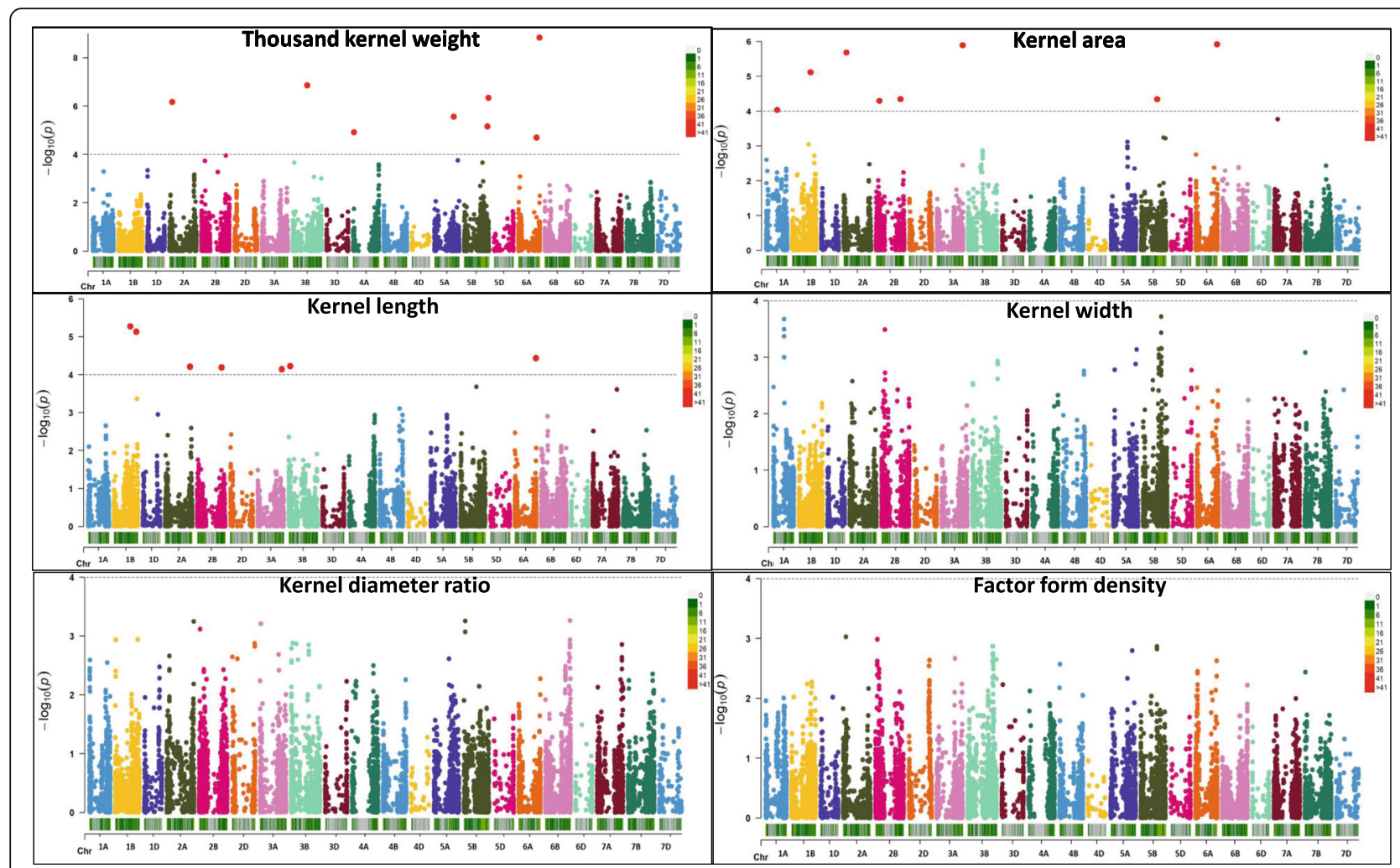

Fig. 3 Manhattan plots showing significant marker-trait associations for six traits related to grain architecture in 261 winter wheat genotypes using BLUEs values. Red dots indicate significant markers $\left(p<0.001 ;-\log _{10}>\right.$ FDR)

results showed that four MTAs across four chromosomes are associated with more than one trait. Those MTAs were detected on 1B (TKW-KA), 2A (TKW-KA), $5 \mathrm{~B}(\mathrm{KA}-\mathrm{KL})$ and 6A (TKW-KA) (Table 2).

\section{Discussion}

\section{Genotypic variability in grain architecture traits}

The identification of factors affecting grain weight and grain architecture is of major importance to accelerate the rate of genetic gain of wheat and increase grain quality. Despite the high number of identified QTL controlling grain morphology in wheat, the implemented studies are scarce or have been carried out partially using bi-parental populations e.g., $\mathrm{DH}$, RILs, and $\mathrm{F}_{2}$ populations $[14,15,21,26,27,34,37,38,44,46]$. This study explores the power of GWAS to identify genomic regions associated with six-grain architecture related-traits in a novel set of 261 winter wheat genotypes, using 17,093 SNP markers in three environments. Our results indicate an extensive phenotypic variation in all traits evaluated across the genotypes. A high heritability (0.87-0.93) and high correlation among environments was observed, indicating the feasibility of this panel for selection of traits related to grain yield and quality improvement [47]. Our results indicate the usefulness of the population used for GWAS studies. In addition, the high diversity of these genotypes can provide more valuable inference compared to bi-parental populations by taking advantage of maximum allelic diversity as was suggested by several authors $[48,49]$. Furthermore, the variation on grain architecture-related traits based on population structure presented significant differences among geographical regions showing that those cultivars from Eastern Europe-Western Asia had higher TKW and KA compared to those from Central-Northern Europe and North America.

\section{Marker-traits association related to grain architecture}

Our analysis detected 17 marker-trait associations related to grain architecture traits across 9 chromosomes, indicates that these are quantitative traits under polygenic control as was reported [26]. These SNPs were passed FDR analysis that provided highly significant true associations ( $P$-values $\geq \mathrm{FDR})$ which can be used in further analysis.

In this study, TKW among 261 winter wheat genotypes showed variability from 31 to $60 \mathrm{~g}$ and 7 MTAs related to this trait were detected on chromosomes $1 \mathrm{~A}$, 2A, 2B, 5B, 6A, and 6B. Previous studies identified QTL on chromosomes $1 \mathrm{~A}$ [50], 2A [9, 26, 42, 51], 2B [9, 40, $52], 3 \mathrm{~A}[40,52-54], 5 \mathrm{~B}[53], 6 \mathrm{~A}[9,50,51]$ and $6 \mathrm{~B}[9$, $26,53]$. To the best of our knowledge, the identified 
MTAs for TKW in this study have not been reported yet and they are potentially novel MTAs responsible for this trait. In addition, candidate genes for TKW have also been identified by several authors $[43,45,55]$ but as far as we know, none of them are coincident with the ones reported in this work and its corresponding functions (Table 2).

In the same way, extensive genotypic variation and significant $G \times E$ interactions were reported for $K A$, $\mathrm{KL}, \mathrm{KW}, \mathrm{FFD}$, and KDR. Although previous studies reported QTL associated with KA $[26,51,56]$, KL [26, 51, 57-59], KW [59], FFD [58], KDR [20, 58, 60], these markers have been documented in different positions to those found in our work, indicating that the associations reported in our work are novel for these traits. Moreover, four novel MTAs across and related to more than one trait (pleiotropic effects) were detected on chromosomes 1B (TKW-KA), 2A (TKWKA), 5B (KA-KL), and 6A (TKW-KA) (Table 2; Fig. 4 and Supplementary Fig. S8).

The identification of underlying genes with annotations related to the grain architecture traits provides further reliability for the MTAs identified in the current study. Although high number of candidate genes have been detected, of which four $\mathrm{HC}$ candidate genes reported in our work have shown effects in other agronomical traits, none of them have been documented as effective on the size, shape, and weight of the grain and can be considered novel.
In this work, we found that the allelic variation at the locus of the gene TraesCS1B01G303200 (chromosome 1B) that annotated as Protein of unknown function DUF1677 (O. sativa) showed its influence on TKW and KA. Even though Gerard et al. [61] documented an effect of this gene on yield-related traits such as grains per spike, the relationship of this gene with grain architecture has not been previously reported.

The candidate gene TraesCS2A01G136800 on chromosome 2A has a role in Heat shock protein (HSP) DnaJ, a cysteine-rich domain, which is a major protein in response to stresses ([62], Preprint). The only protein of known function from plants that contains the Cysrich domain of DnaJ-like proteins is maize BSD2 [63]. The DnaJ-like proteins with other HSP are considered important components in the cytosol and organelles for protein metabolism [64]. Heat stress during the grain filling stage affects the translocation of photosynthates to the grains and the synthesis and deposition of starch [65], resulting in TKW reductions and alterations in the grain morphology. The recent report mention that, the growing season 2017/2018 was the mostest dryness season in IPK since long-ago that influnce spikelet development and abortion in barley [66], that can also explain the effect of heat (high temperture) on the TKW. The synthesis of HSPs is believed to play an important role either in preventing or minimizing the negative effects of high temperature both at the cellular and molecular levels. This gene was related to TKW and KA suggesting

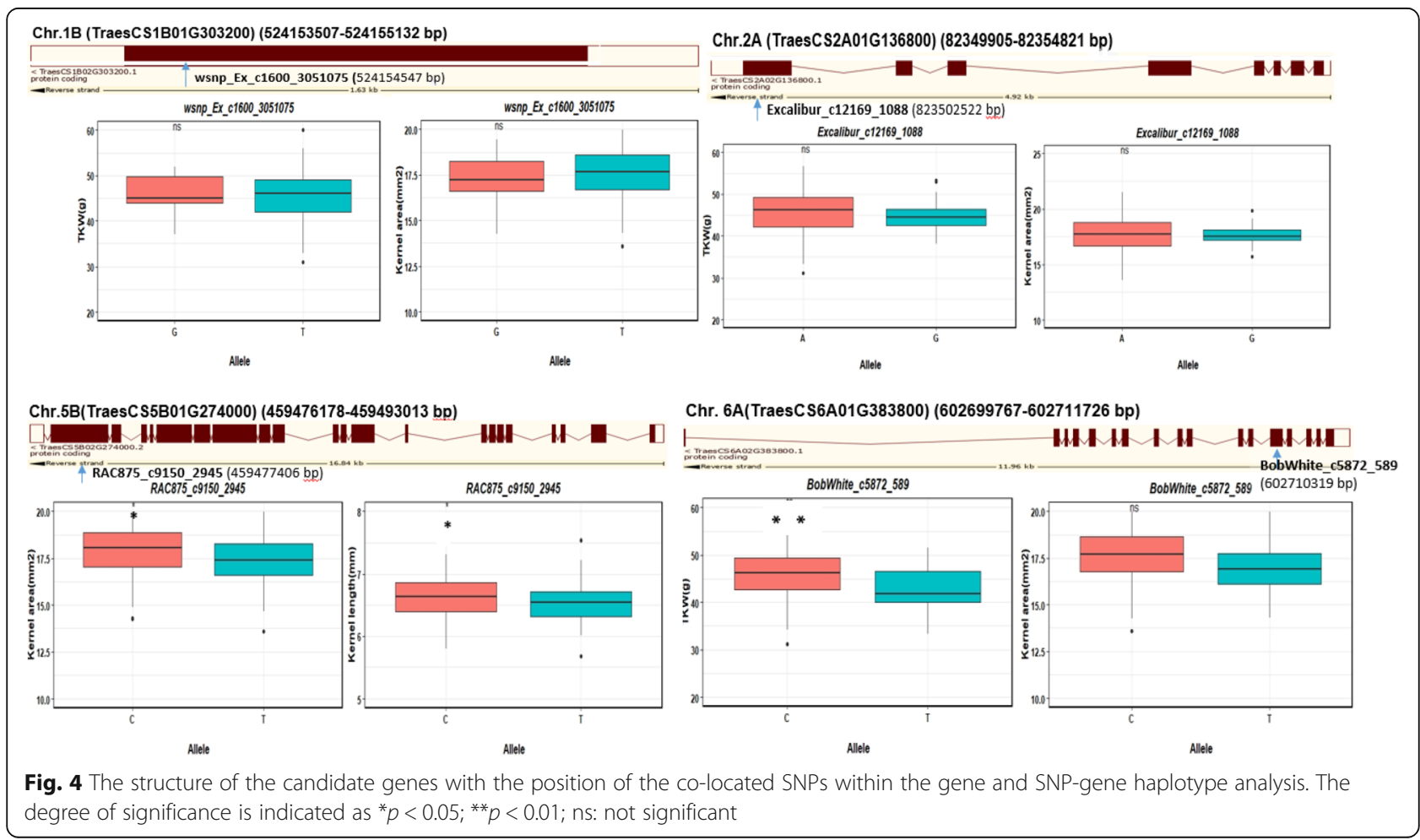


its important role in controlling grain weight and architecture that needs further molecular validation. A recent report from $\mathrm{Hu}$ et al. [67] documented 3 QTLs associated with heading date (QHD-2A.1), spikelet per spike (QSPS-2A.3), and flag leaf area (QFLA-2A.1) in this region but no effects on grain characteristics have been documented so far.

The candidate gene TraesCS5B01G274000 on chromosome 5B, annotates P-loop containing nucleoside triphosphate hydrolase (NTPase) which is the most common domain of many nucleotide-binding protein folds. The energy from NTP hydrolysis is typically utilized to induce conformational changes in other molecules, which constitutes the basis of the biological functions of most P-loop NTPases. P-loop NTPases show substantial substrate preference for either ATP or GTP [68]. Although this gene was linked to KA and KL and its role in those important biological functions may derive from this association with grain morphology, its relationship with these treatments has not been previously documented.

The last identified candidate gene TraesCS6A01G383800 (chromosome 6A) encodes oxidoreductase activity, acting on a sulfur group of donors, NAD(P) as acceptor. It has been reported that GSH-dependent protein-disulphide oxidoreductase (TPDO) increases the activity in a period of maximum synthesis of storage proteins in wheat grains, which is the third week after anthesis. There is a correlation between TPDO activity in maturing grains and dough extensibility as the enzyme reduces SS bonds in high-molecular-weight polymers [69]. This higher accumulation could result in TKW and KA increases. Effects of this gene were reported on grain quality traits such as Falling Number and root architecture of durum wheat [70] but no association with TKW and KA was reported previously. The high expression of these four candidate genes in different grain related-tissues indicates their important biological role in variables connected to grain architecturerelated traits (Fig. 5).

As was previously described, we found that the TraesCS1A01G007200 gene located on chromosome 1A associated with TKW and with a weaker association with KA has a nutrient reservoir activity molecular function and annotates Gliadin/LMW glutenin//Bifunctional inhibitor/plant lipid transfer protein/seed storage helical domain. It is known that gliadin and glutenin proteins have a major role in grain quality determination [71]. Its role is explained as gliadins and glutenins are the major reserve proteins in wheat [72], forming the gluten and contributing to TKW. Although recent studies reported effects of this gene on gliadin synthesis in durum wheat and heading-anthesis date in hexaploid wheat [73, 74], its effect on traits related to grain architecture and TKW has not been reported so far.

The highly significant SNPs within the candidate genes were analyzed using statistical comparison of alleles at each SNP with the associated traits. This approach have

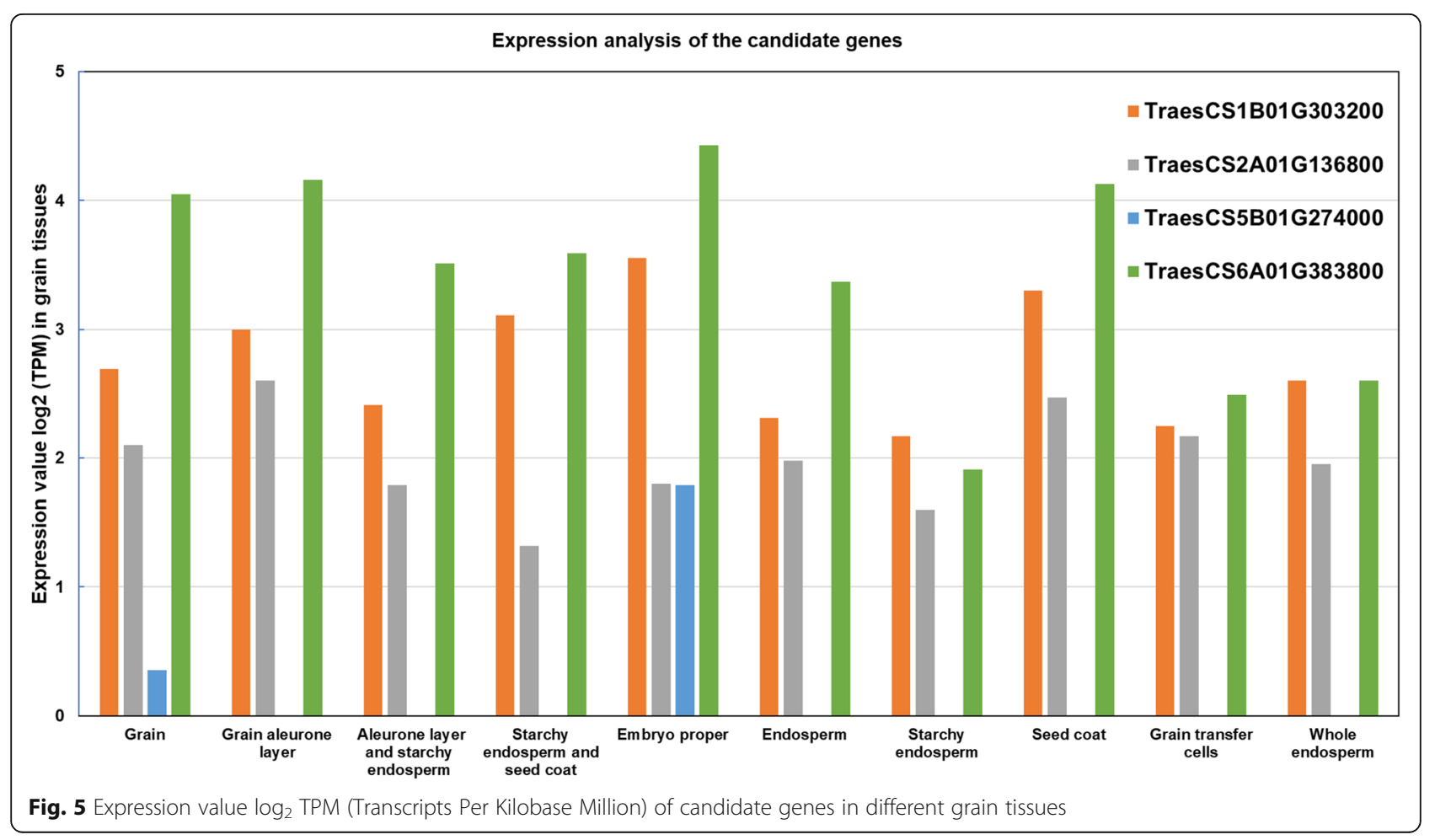


been used recently to explore the alleles for enhancing agronomic traits and abiotic tolerance [12, 75, 76]. The results showed that some SNPs within the candidate genes showed significant differences between alleles of each associated trait considered. Accessions were differentiated according to the alleles which demonstrate their impact on grain architecture-related traits. For example, the allelic variation $(\mathrm{C}, \mathrm{T})$ at SNPs BobWhite_c5872_589 underlying the genes TraesCS6A01G383800, respectively, showed the importance of allele $\mathrm{C}$ in increasing TKW, where most of the accessions carried allele C originated mainly from Central-Northern European countries.

\section{Conclusions}

To our knowledge, our study involves the first GWAS analysis performed by FARM-CPU algorithm to identify several key genomic regions associated with TKW and five other grain architecture traits in a new and wide winter wheat panel consisting of 261 genotypes from 30 countries during three years. Genome-wide association analysis using $90 \mathrm{~K} \mathrm{SNP}$ array revealed many MTAs including 17 highly associated SNPs across 9 chromosomes of which four multi-traits associated SNPs were found on chromosomes $1 \mathrm{~B}, 2 \mathrm{~A}, 5 \mathrm{~B}$, and $6 \mathrm{~A}$. We reported four novel candidate genes related to these traits showing high expression values in different grain tissues.

Future studies should deepen the relationships between the function of these genes and their effect on grain architecture. These results will be valuable for identifying regions associated with kernel weight and its dimensions and could be useful for providing further insights for increasing grain quality, milling performance, and grain yield.

\section{Methods}

\section{Plant materials}

In the current study, a winter wheat panel was used comprising 261 accessions including 196 cultivars, 55 breeding lines, and 10 doubled haploids originated from 30 countries worldwide. The seeds of these genotypes were obtained from the Genebank, IPK-Gatersleben, Germany. The accessions were selected based on preexisting knowledge regarding their performance under different growing conditions during winter time, for instance, high latitude and continental European winter wheat collections as well as Russian and North American cultivars. Furthermore, parts of the core collection of the Institute of Field and Vegetable Crops (IFVCNS), Novi Sad, Serbia and parental lines of Western European hybrid breeding programs were also included in this set ([77]; Supplementary Fig. S1; Table S1).

\section{Grain architecture traits assessments/phenotyping/ measurements}

Field experiments were carried out at Leibniz Institute of Plant Genetics and Crop Plant Research -IPK- (Gatersleben, Germany) over three consecutive years (2015/ 2016, 2016/2017 and 2017/2018) with three replicated blocks in $5 \mathrm{~m}^{2}$ plots for each accession.

After harvesting, 200 random kernels of each plot (per accession and year) were used to assess kernel size traits including, kernel length ( $\mathrm{KL} ; \mathrm{mm})$, kernel width (KW; $\mathrm{mm})$, kernel area (KA; $\left.\mathrm{mm}^{2}\right)$ and TKW (g) using the MARVIN Digital Seed Analyser (MARViTECH GmbH, Germany). In addition, to evaluate the differences in grain density and the deviation of a shape from a cylindrical form, the factor form density (FFD) and kernel diameter ratio (KDR) were calculated according to Giura and Saulescu [13] and Gegas et al. [15] using the following equations:

$$
\begin{aligned}
& F F D=T K W /(K L * K W) \\
& K D R=K L / K W
\end{aligned}
$$

\section{Statistical analysis}

Analysis of variance (ANOVA) for all measured traits was performed and broad-sense heritability $\left(H^{2}\right)$ for each trait over years was calculated using the following equation, all these calculations were accomplished using Genstat 19:

$$
H^{2}=\sigma g^{2} /\left(\frac{\sigma \mathrm{y}^{2}}{\mathrm{y}}+\frac{\sigma \mathrm{e}^{2}}{\mathrm{ry}}\right)
$$

where $\sigma g^{2}, \sigma g y^{2}$, and $\sigma e^{2}$ are mean squares for genotype, genotype $\times$ year (environment) interaction and residual error, respectively, $y$ is the number of years and $r$ represent the replicates. Summary statistics across different years were corroborated by mean, minimum, maximum, standard deviation and coefficient of variation using Genstat 19 software. A correlation matrix between traits and boxplots of each trait and differences among geographical regions were performed using MVApp v2.0.

The restricted maximum likelihood (REML) algorithm was applied to calculate the Best Linear Unbiased Estimators (BLUEs) for each trait in each accession across the years by considering the accession as a fixed effect and the environment as a random using Linear and Nonlinear Mixed Effects Models (nlme) package in R [78].

\section{Genotyping and population structure}

The panel was genotyped by TraitGenetics $\mathrm{GmbH}$ (http://www.traitgenetics.com) the $90 \mathrm{~K}$ iSELECT chip [79]. After removing markers with $>10 \%$ missing data and those with the minor allele frequency $<5 \%, 17,093$ 
SNPs remained (Supplementary Fig. S2). These markers were mapped according to their physical position based on IWGSC RefSeq v1.1 (http://www.wheatgenome.org/, IWGSC RefSeq v1.1) and then used to determine the population structure, linkage disequilibrium (LD) and for GWAS calculation. The genome-wide pairwise estimates of LD were calculated as a squared correlation between pairs of polymorphic SNPs $\left(\mathrm{r}^{2}\right)$ for the wholegenome using GenStat 18 [80]. Finally, LD decay patterns were visualized as the plot for the LD estimated the $\left(r^{2}\right)$ vs. the distance between pairs of polymorphic SNPs (Mbp) using R-package GGPLOT2 [81]. The average genome-wide LD decay at $r^{2}=0.2$ is approximately 2.0 Mbp and we used this window to discover the candidate genes with a reasonable distance as suggested by 3 . The genetic relationships among genotypes as the population structure were revealed by principal component analysis (PCA), using Genomic Association and Prediction Integrated Tool (GAPIT 3) package in R $[82,83]$. In the present study, the population structure of a diverse panel of 261 wheat genotypes was investigated using the basis of a $90 \mathrm{~K} \mathrm{SNP}$ chip to specify the number of principal components (PCs) to be included in the GWAS model (Supplementary Fig. S3).

\section{Genome-wide association study and identifying putative candidate genes}

GWAS was performed using BLUEs values in each accession for each trait applying different statistical models through GAPIT in R. FARM-CPU model was applied by considering the random effect model (REM) and the fixed effect model (FEM) iteratively and associated markers as a cofactor that empowered us to avoid any false-negative and control the false positive associations by preventing model overfitting [27, 40, 57, 84-86]. FarmCPU joins the advantages of the mixed linear model and stepwise regression (fixed-effect model) and overcomes their disadvantages by using them iteratively. FarmCPU has higher power and fewer false positives than either MLM or stepwise regression. The detected associations which are passed the threshold of FDR at $0.01\left(-\log _{10} P\right.$-values $\geq$ FDR $)$ were considered as significant marker-trait associations (MTAs). FDR was calculated for each trait separately at the significance level of 0.01 and used in further analyses as recommended by Alqudah et al. [75].

Those highly significant MTAs based on their physical positions were further used to identify the highconfidence (HC) putative candidate genes, based on their physical positions within the LD $\pm 2 \mathrm{Mbp}$ window, using the reference genome sequence of Chinese Spring by blasting against IWGSC RefSeq annotation v1.1 (http://www.wheatgenome.org/, IWGSC RefSeq v1.1). Because, each block of LD contains high number of candidate genes, we have selected the candidate genes which have SNPs within their physical positions. WheatMine platform (https://urgi.versailles.inra.fr/WheatMine/ begin.do) was used to search for the gene ontologies (GO) and InterPro number and description. The underlying genes were further examined for their association with grain architecture traits using previously published literature.

In-silico gene expression analysis in different grain tissues of the multi-traits candidate genes was analyzed using RNA-Seq expression data from Wheat Expression Browser (http://www.wheat-expression.com/).

\section{Abbreviations}

ANOVA: Analysis of variance; BLUE: Best Linear Unbiased Estimators; FFD: Factor form density; FDR: False discovery rate; GWAS: Genome-wide association study; $H^{2}$ : Broad-sense heritability; IWGSC: International Wheat Genome Consortium; KA: Kernal area; KDR: Kernel diameter ratio; KL: Kernel length; KW: Kernel width; LD: Linkage disequilibrium; MAF: Minor allele frequency; PC: Principal component; REML: Residual maximum likelihood; SNP: Single nucleotide polymorphism; TKW: Thousand kernel weight

\section{Supplementary Information}

The online version contains supplementary material available at https://doi. org/10.1186/s12870-021-03183-3.

Additional file 1: Table S1. Information about the source, country of origin and biological status of the winter wheat panel. Table S2. Summary statistics of Thousand-kernel weight (TKW), Kernel length (KL), Kernel width (KW), Kernel area (KA), Kernel diameter ratio (KDR) and Factor form density (FFD) in an experiment with 261 wheat genotypes evaluated during 3 years. Table S3. Significant marker-trait associations and candidate genes for grain architecture traits in 261 winter wheat genotypes.

Additional file 2: Table S4. List of candidate genes within the most important four LD blocks.

Additional file 3: Figure S1. Origin of the genotypes of the panel. Figure S2. Single nucleotide polymorphism (SNP) density on 21 wheat chromosomes. The $\mathrm{x}$-axis shows the interval distance in Mb. Figure $\mathbf{S 3}$. Screen plot for the first ten principal components (PCs) explains the variation using 90K chip and Population structure based on their origin. Figure S4. Kinship heat map of the panel. Figure S5. The linkage disequilibrium decay in the wheat population. Figure S6. Phenotypic variation and Heritability $\left(H^{2}\right)$ for Thousand-kernel weight (TKW), Kernel length (KL), Kernel width (KW), Kernel area (KA), Kernel diameter ratio (KDR) and Factor form density (FFD) using BLUEs values. Figure S7. Variation on Thousand-kernel weight (TKW), Kernel length (KL), Kernel width $(\mathrm{KW})$, Kernel area (KA), Kernel diameter ratio (KDR) and Factor form density (FFD) based on the origin of genotypes. C-N Europe (central-northern Europe); E Europe-W Asia (Eastern Europe-Western Asia); N America (North America). Figure S8. Overview of significant markers trait associations identified for Thousand-kernel weight (TKW), Kernel length (KL), Kernel width (KW), Kernel area (KA), Kernel diameter ratio (KDR) and Factor form density (FFD) using BLUEs values. Multitraits MTAs are indicated with gray rectangles.

\section{Acknowledgments}

We thank IPK staff for technical assistance in field trials.

\section{Authors' contributions}

MS, AMA and AB designed and supervised the research. MS, AMA, MRS, RT and UL analyzed data. AB provided genotypic resources for the analysis. MS and AMA interpret of results and wrote the manuscript. All authors have read and agreed to the published version of the manuscript. The author(s) read and approved the final manuscript 


\section{Funding}

This study was supported by core funding of the Leibniz Institute of Plant Genetics and Crop Plant Research. M.S. appreciates the support received by Jeff Schell Scholarship from Bayer Foundation, Leibniz-DAAD Research Fellowship and Georg Forster Fellowship from Alexander von Humboldt Foundation. This study was part of GRAINY "NNF200C0064295" project funded by the Novo Nordisk Foundation for A.M.A. The funding bodies played no role in the design of the study and collection, analysis, and interpretation of data and in writing the manuscript. Open Access funding enabled and organized by Projekt DEAL.

\section{Availability of data and materials}

The datasets supporting the conclusions of this article are included within the article and its supplementary materials published online or are available from the corresponding author on reasonable request. Further information regarding the GenBank accessions including accession name, number and source are available by Babben et al., [7] and Table S1. All accessions used in the current study are publicly available from IPK Gatersleben Genebank.

\section{Declarations}

\section{Ethics approval and consent to participate}

Not applicable.

\section{Consent for publication}

Not applicable.

\section{Competing interests}

The authors declare no conflict of interest.

\section{Author details}

'Genebank Department, Leibniz Institute of Plant Genetics and Crop Plant Research (IPK), OT Gatersleben, Corrensstr 3, D-06466 Seeland, Germany. ${ }^{2}$ Cereals, Faculty of Agricultural Sciences and Forestry, National University of La Plata, La Plata, Argentina. ${ }^{3}$ CONICET CCT La Plata. La Plata, Buenos Aires, Argentina. ${ }^{4}$ Department of Agroecology, Aarhus University at Flakkebjerg, Forsøgsvej 1, 4200 Slagelse, Denmark.

\section{Received: 26 February 2021 Accepted: 20 August 2021}

\section{Published online: 10 September 2021}

\section{References}

1. Hall AJ, Richards RA. Prognosis for genetic improvement of yield potential and water-limited yield of major grain crops. Field Crops Res. 2013;143:1833 https://doi.org/10.1016/j.fcr.2012.05.014.

2. Ferrante A, Cartelle J, Savin R, Slafer GA. Yield determination, interplay between major components and yield stability in a traditional and a contemporary wheat across a wide range of environments. Field Crops Res. 2017;203:114-27 https://doi.org/10.1016/j.fcr.2016.12.028.

3. Voss-Fels KP, Keeble-Gagnère G, Hickey LT, Tibbits J, Nagornyy S, Hayden MJ, et al. High-resolution mapping of rachis nodes per rachis, a critical determinant of grain yield components in wheat. Theor Appl Genet. 2019; 132(9):2707-19 https://doi.org/10.1007/s00122-019-03383-4.

4. Sanchez-Garcia M, Royo C, Aparicio N, Martín-Sánchez JA, Alvaro F. Genetic improvement of bread wheat yield and associated traits in Spain during the 20th century. J Agric Sci. 2013;151(1):105-18 https://doi.org/10.1017/S0021 859612000330.

5. Lopes MS, Reynolds MP, Jalal-Kamali MR, Moussa M, Feltaous Y, Tahir ISA, et al. The yield correlations of selectable physiological traits in a population of advanced spring wheat lines grown in warm and drought environments. Field Crops Res. 2012;128:129-36 https://doi.org/10.1016/j.fcr.2011.12.017.

6. Yang J, Zhou Y, Wu Q, Chen Y, Zhang P, Zhang Y, et al. Molecular characterization of a novel TaGL3-5A allele and its association with grain length in wheat (Triticum aestivum L.). Theor Appl Genet. 2019;132(6):1799814 https://doi.org/10.1007/s00122-019-03316-1.

7. Griffiths S, Wingen L, Pietragalla J, Garcia G, Hasan A, Miralles D, et al. Genetic dissection of grain size and grain number trade-offs in CIMMYT wheat germplasm. PLoS One. 2015;10(3):e0118847 https://doi.org/10.1371/ journal.pone.0118847.
8. Pinthus MJ, Millet E. Interactions among number of spikelets, number of grains and grain weight in the spikes of wheat (Triticum aestivum L.). Ann Bot. 1978;42(4):839-48 https://doi.org/10.1093/oxfordjournals.aob.a085523.

9. Sukumaran S, Lopes M, Dreisigacker S, Reynolds M. Genetic analysis of multi-environmental spring wheat trials identifies genomic regions for locus-specific trade-offs for grain weight and grain number. Theor Appl Genet. 2018;131(4):985-98 https://doi.org/10.1007/s00122-017-3037-7.

10. Wolde GM, Mascher M, Schnurbusch T. Genetic modification of spikelet arrangement in wheat increases grain number without significantly affecting grain weight. Mol Gen Genomics. 2019;294(2):457-68 https://doi. org/10.1007/s00438-018-1523-5.

11. Tshikunde NM, Mashilo J, Shimelis H, Odindo A. Agronomic and physiological traits, and associated quantitative trait loci (QTL) affecting yield response in wheat (Triticum aestivum L.): A review. Front Plant Sci. 2019;10:1428.

12. Alqudah AM, Haile JK, Alomari DZ, Pozniak CJ, Kobiljski B, Börner A. Genome-wide and SNP network analyses reveal genetic control of spikelet sterility and yield-related traits in wheat. Sci Rep. 2020a;10(1):2098 https:// doi.org/10.1038/s41598-020-59004-4.

13. Giura A, Saulescu NN. Chromosomal location of genes controlling grain size in a large grained selection of wheat (Triticum aestivum L.). Euphytica. 1996; 89(1):77-80 https://doi.org/10.1007/BF00015722.

14. Sehgal D, Mondal S, Guzman C, Garcia Barrios G, Franco C, Singh R, et al. Validation of candidate gene-based markers and identification of novel loci for thousand-grain weight in spring bread wheat. Front Plant Sci. 2019;10: 1189 https://doi.org/10.3389/fpls.2019.01189.

15. Gegas VC, Nazari A, Griffiths S, Simmonds J, Fish L, Orford S, et al. A genetic framework for grain size and shape variation in wheat. Plant Cell. 2010;22(4): 1046-56 https://doi.org/10.1105/tpc.110.074153.

16. Marshall DR, Mares DJ, Moss HJ, Ellison FW. Effects of grain shape and size on milling yields in wheat. II. Experimental studies. Aust J Agric Res. 1986; 37(4):331.

17. Wiersma JJ, Busch RH, Fulcher GG, Hareland GA. Recurrent selection for kernel weight in spring wheat. Crop Sci. 2001;41(4):999-1005 https://doi. org/10.2135/cropsci2001.414999x.

18. Novaro P, Colucci F, Venora G, D'Egidio MG. Image analysis of whole grains: a noninvasive method to predict semolina yield in durum wheat. Cereal Chem. 2001;78(3):217-21 https://doi.org/10.1094/CCHEM.2001.78.3.217.

19. Osborne BG, Anderssen RS. Single-kernel characterization principles and applications. Cereal Chem. 2003;80(5):613-22 https://doi.org/10.1094/ CCHEM.2003.80.5.613.

20. Su Q, Li J. QTL detection for kernel size and weight in bread wheat (Triticum aestivum L.) using a high-density SNP and SSR-based linkage map. Front Plant Sci. 2018;9:1484.

21. Breseghello F, Sorrells ME. Association mapping of kernel size and milling quality in wheat (Triticum aestivum L.) cultivars. Genetics. 2006;172(2):116577 https://doi.org/10.1534/genetics.105.044586.

22. Evers AD, Cox RI, Shaheedullah MZ, Withey RP. Predicting milling extraction rate by image analysis of wheat grains. Asp Appl Biol. 1990;25:417-26.

23. Millar SJ, Whitworth MB, Evers AD. Image analysis: the prediction and assessment of wheat quality and milling properties. Manhattan: Grain Industry Alliance; 1997. p. 141-51.

24. Morgan BC, Dexter JE, Preston KR. Relationship of kernel size to flour water absorption for Canada western red spring wheat. Cereal Chem. 2000;77(3): 286-92 https://doi.org/10.1094/CCHEM.2000.77.3.286.

25. Cao S, Xu D, Hanif M, Xia X, He Z. Genetic architecture underpinning yield component traits in wheat. Züchter Genet Breed Res. 2020;133(6):1811-23.

26. Li F, Wen W, Liu J, Zhang Y, Cao S, He Z, et al. Genetic architecture of grain yield in bread wheat based on genome-wide association studies. BMC Plant Biol. 2019a;19(1):168 https://doi.org/10.1186/s12870-019-1781-3.

27. Muhammad A, Hu W, Li Z, Li J, Xie G, Wang J, et al. Appraising the genetic architecture of kernel traits in hexaploid wheat using GWAS. Int J Mol Sci. 2020;21(16):5649 https://doi.org/10.3390/ijms21165649.

28. Sehgal D, Mondal S, Crespo-Herrera L, Velu G, Juliana P, Huerta-Espino J, et al. Haplotype-based, genome-wide association study reveals stable genomic regions for Grain yield in CIMMYT Spring Bread Wheat. Front Genet. 2020; $11: 1427$.

29. Reynolds MP, Pask AJD, Hoppitt WJE, Sonder K, Sukumaran S, Molero G, et al. Correction to: strategic crossing of biomass and harvest index-source and sink-achieves genetic gains in wheat. Euphytica. 2018;214(1):9 https://doi. org/10.1007/s10681-017-2086-y. 
30. Zhang $Y, X u$ W, Wang H, Dong H, Qi X, Zhao M, et al. Progress in genetic improvement of grain yield and related physiological traits of Chinese wheat in Henan Province. Field Crops Res. 2016;199:117-28 https://doi.org/1 0.1016/j.fcr.2016.09.022.

31. Ayoub M, Mather DE. Effectiveness of selective genotyping for the detection of quantitative trait loci: an analysis of grain and malt quality traits in three barley populations. Genome. 2002;45(6):1116-24 https://doi.org/1 $0.1139 / \mathrm{g} 02-089$

32. Li Y, Fan C, Xing Y, Jiang Y, Luo L, Sun L, et al. Natural variation in GS5 plays an important role in regulating grain size and yield in rice. Nat Genet. 2011; 43(12):1266-9 https://doi.org/10.1038/ng.977.

33. Nadolska-Orczyk A, Rajchel IK, Orczyk W, Gasparis S. Major genes determining yield-related traits in wheat and barley. Theor Appl Genet. 2017;130(6):1081-98 https://doi.org/10.1007/s00122-017-2880-x.

34. Kumar A, Mantovani EE, Seetan R, Soltani A, Echeverry-Solarte M, Jain S, et al. Dissection of genetic factors underlying wheat kernel shape and size in an elite $\times$ nonadapted cross using a high density SNP linkage map. Plant Genome 2016;9(1). Available from. https://doi.org/10.3835/plantgenome201 5.09.0081.

35. Ramya P, Chaubal A, Kulkarni K, Gupta L, Kadoo N, Dhaliwal HS, et al. QTL mapping of 1000-kernel weight, kernel length, and kernel width in bread wheat (Triticum aestivum L.). J Appl Genet. 2010;51(4):421-9 https://doi. org/10.1007/BF03208872.

36. Cabral AL, Jordan MC, Larson G, Somers DJ, Humphreys DG, McCartney CA. Relationship between QTL for grain shape, grain weight, test weight, milling yield, and plant height in the spring wheat cross RL4452/'AC Domain'. PLoS One. 2018;13(1):e0190681 https://doi.org/10.1371/journal. pone.0190681.

37. Tsilo TJ, Hareland GA, Simsek S, Chao S, Anderson JA. Genome mapping of kernel characteristics in hard red spring wheat breeding lines. Theor Appl Genet. 2010;121(4):717-30 https://doi.org/10.1007/s00122-010-1343-4.

38. Williams K, Sorrells ME. Three-dimensional seed size and shape QTL in hexaploid wheat (Triticum aestivum L.) populations. Crop Sci. 2014;54(1):98110 https://doi.org/10.2135/cropsci2012.10.0609.

39. Okamoto Y, Nguyen AT, Yoshioka M, lehisa JCM, Takumi S. Identification of quantitative trait loci controlling grain size and shape in the $\mathrm{D}$ genome of synthetic hexaploid wheat lines. Breed Sci. 2013;63(4):423-9 https://doi. org/10.1270/jsbbs.63.423.

40. Bhatta M, Morgounov A, Belamkar V, Baenziger PS. Genome-wide association study reveals novel genomic regions for grain yield and yieldrelated traits in drought-stressed synthetic hexaploid wheat. Int J Mol Sci. 2018;19(10) Available from: https://doi.org/10.3390/ijms19103011.

41. Mohler V, Albrecht T, Castell A, Diethelm M, Schweizer G, Hartl L. Considering causal genes in the genetic dissection of kernel traits in common wheat. J Appl Genet. 2016;57(4):467-76 https://doi.org/10.1007/ s13353-016-0349-2.

42. Würschum T, Leiser WL, Langer SM, Tucker MR, Longin CFH. Phenotypic and genetic analysis of spike and kernel characteristics in wheat reveals longterm genetic trends of grain yield components. Theor Appl Genet. 2018; 131(10):2071-84 https://doi.org/10.1007/s00122-018-3133-3.

43. Ye X, Li J, Cheng Y, Yao F, Long L, Wang Y, et al. Genome-wide association study reveals new loci for yield-related traits in Sichuan wheat germplasm under stripe rust stress. BMC Genomics. 2019;20(1):640 https://doi.org/10.11 86/s12864-019-6005-6.

44. Sun J, Poland JA, Mondal S, Crossa J, Juliana P, Singh RP, et al. Highthroughput phenotyping platforms enhance genomic selection for wheat grain yield across populations and cycles in early stage. Theor Appl Genet. 2019;132(6):1705-20 https://doi.org/10.1007/s00122-019-03309-0.

45. Mangini G, Blanco A, Nigro D, Signorile MA, Simeone R. Candidate genes and quantitative trait loci for grain yield and seed size in durum wheat. Plants. 2021;10(2):312 https://doi.org/10.3390/plants10020312.

46. Huang XQ, Cloutier S, Lycar L, Radovanovic N, Humphreys DG, Noll JS, et al. Molecular detection of QTLs for agronomic and quality traits in a doubled haploid population derived from two Canadian wheats (Triticum aestivum L.). Theor Appl Genet. 2006;113(4):753-66 https://doi.org/10.1007/s00122006-0346-7.

47. Gao Y, Xu X, Jin J, Duan S, Zhen W, Xie C, et al. Dissecting the genetic basis of grain morphology traits in Chinese wheat by genome wide association study. Euphytica. 2021;217(4):1-12.

48. Ayalew H, Liu H, Börner A, Kobiljski B, Liu C, Yan G. Genome-wide association mapping of major root length QTLs under PEG induced water stress in wheat. Front Plant Sci. 2018:9:1759 https://doi.org/10.3389/fpls.201 8.01759.

49. Mathew I, Shimelis H, Shayanowako AIT, Laing M, Chaplot V. Genome-wide association study of drought tolerance and biomass allocation in wheat. PLoS One. 2019;14(12):e0225383 https://doi.org/10.1371/journal. pone.0225383.

50. Ogbonnaya FC, Rasheed A, Okechukwu EC, Jighly A, Makdis F, Wuletaw T, et al. Genome-wide association study for agronomic and physiological traits in spring wheat evaluated in a range of heat prone environments. Theor Appl Genet. 2017;130(9):1819-35 https://doi.org/10.1007/s00122-017-2927-z.

51. Li T, Liu H, Mai C, Yu G, Li H, Meng L, et al. Variation in allelic frequencies at loci associated with kernel weight and their effects on kernel weight-related traits in winter wheat. Crop J. 2019b;7(1):30-7 https://doi.org/10.1016/j.cj.201 8.08.002.

52. Lozada DN, Mason RE, Babar MA, Carver BF, Guedira G-B, Merrill K, et al. Association mapping reveals loci associated with multiple traits that affect grain yield and adaptation in soft winter wheat. Euphytica 2017;213(9). Available from. https://doi.org/10.1007/s10681-017-2005-2.

53. Sun CW, Zhang FY, Yan XF, Zhang XF, Dong ZD, Cui DQ, et al. Genome wide association study for 13 agronomic traits reveals distribution of superior alleles in bread wheat from the yellow and Huai Valley of China. Plant Biotechnol J. 2017;15(8):953-69 https://doi.org/10.1111/pbi.12690.

54. Zanke CD, Ling J, Plieske J, Kollers S, Ebmeyer E, Korzun V, et al. Analysis of main effect QTL for thousand grain weight in European winter wheat (Triticum aestivum L.) by genome-wide association mapping. Front. Plant Sci. 2015;6:644.

55. Giancaspro A, Giove SL, Zacheo SA, Blanco A, Gadaleta A. Genetic variation for protein content and yield-related traits in a durum population derived from an inter-specific cross between hexaploid and tetraploid wheat cultivars. Front Plant Sci. 2019;10:1509 https://doi.org/1 0.3389/fpls.2019.01509.

56. Kumari S, Jaiswal V, Mishra VK, Paliwal R, Balyan HS, Gupta PK. QTL mapping for some grain traits in bread wheat (Triticum aestivum L.). Physiol Mol Biol Plants. 2018:24(5):909-20 https://doi.org/10.1007/s12298-018-0552-1.

57. Arora S, Singh N, Kaur S, Bains NS, Uauy C, Poland J, et al. Genome-wide association study of grain architecture in wild wheat Aegilops tauschii. Front Plant Sci. 2017:8:886 https://doi.org/10.3389/fpls.2017.00886.

58. Wang S, Xu S, Chao S, Sun Q, Liu S, Xia G. A genome-wide association study of highly heritable agronomic traits in durum wheat. Front Plant Sci. 2019; 10:919 https://doi.org/10.3389/fpls.2019.00919.

59. Xuefang Y, Zhao L, Ren Y, Zhongdong D, Dangqun C, Chen F. Genomewide association study revealed that the TaGW8 gene was associated with kernel size in Chinese bread wheat; 2019.

60. Wang S-X, Zhu Y-L, Zhang D-X, Shao H, Liu P, Hu J-B, et al. Genome-wide association study for grain yield and related traits in elite wheat varieties and advanced lines using SNP markers. PLoS One. 2017;12(11):e0188662 https://doi.org/10.1371/journal.pone.0188662.

61. Gerard GS, Alqudah A, Lohwasser U, Börner A, Simón MR. Uncovering the genetic architecture of fruiting efficiency in bread wheat: a viable alternative to increase yield potential. Crop Sci. 2019;59(5):1853-69 https://doi.org/1 0.2135/cropsci2018.10.0639.

62. Zhang H, Guo H, Wang G, Wang C, Wang Y, Liu X, et al. Identification and expression analysis of heat shock proteins in wheat infected with powdery mildew and stripe rust. bioRxiv. 2020. Available from:. https://doi.org/10.11 01/2020.03.26.010801.

63. Brutnell TP, Sawers RJH, Mant A, Langdale JA. BUNDLE SHEATH DEFECTIVE2, a novel protein required for post-translational regulation of the $r b c L$ gene of maize. Plant Cell. 1999;11(5):849-64 https://doi.org/10.1105/tpc.11.5.849.

64. Martin J, Hartl FU. Molecular chaperones in cellular protein folding. Bioessays. 1994;16(9):689-92 https://doi.org/10.1002/bies.950160916.

65. Sehgal A, Sita K, Siddique KHM, Kumar R, Bhogireddy S, Varshney RK, et al. Drought or/and heat-stress effects on seed filling in food crops: impacts on functional biochemistry, seed yields, and nutritional quality. Front Plant Sci. 2018;9:1705 https://doi.org/10.3389/fpls.2018.01705.

66. Ahmad M. Alqudah Rajiv, Sharma Andreas, Börner Insight into the genetic contribution of maximum yield potential spikelet development and abortion in barley. PLANTS PEOPLE PLANET. https://doi.org/10.1002/ppp3.1 0203.

67. Hu J, Wang $X$, Zhang G, Jiang P, Chen W, Hao Y, et al. QTL mapping for yield-related traits in wheat based on four RIL populations. Theor Appl Genet. 2020;133(3):917-33 https://doi.org/10.1007/s00122-019-03515-W. 
68. Leipe DD, Koonin EV, Aravind L. STAND, a class of P-loop NTPases including animal and plant regulators of programmed cell death: multiple, complex domain architectures, unusual phyletic patterns, and evolution by horizontal gene transfer. J Mol Biol. 2004;343(1):1-28 https://doi.org/10.1016/j.jmb.2004. 08.023.

69. Osipova S, Permyakov A, Mitrofanova T, Trufanov V, Ermakova M, Chistyakova A, et al. GSH-dependent proteindisulphide oxidoreductase of wheat grain: activity in maturing wheat kernels, and relationship with rheological properties of dough. Cereal Res Commun. 2007;35(3):1477-86 https://doi.org/10.1556/CRC.35.2007.3.12.

70. Alahmad S, El Hassouni K, Bassi FM, Dinglasan E, Youssef C, Quarry G, et al. A major root architecture QTL responding to water limitation in durum wheat. Front Plant Sci. 2019;10:436

71. Schofield JD. Wheat proteins: structure and functionality in milling and breadmaking. Wheat: Springer US; 1994. p. 73-106.

72. Triboï E, Martre P, Triboï-Blondel A-M. Environmentally-induced changes in protein composition in developing grains of wheat are related to changes in total protein content. J Exp Bot. 2003;54(388):1731-42 https://doi.org/10.1 093/jxb/erg 183.

73. Hao C, Jiao C, Hou J, Li T, Liu H, Wang Y, et al. Resequencing of 145 landmark cultivars reveals asymmetric sub-genome selection and strong founder genotype effects on wheat breeding in China. Mol Plant. 2020; 13(12):1733-51 https://doi.org/10.1016/j.molp.2020.09.001.

74. Nigro D, Monaci L, Pilolli R, Gadaleta A. Allelic variation of gliadin-encoding genes in a collection of tetraploid wheat genotypes. Cereal Res Commun. 2020:48(4):507-15 https://doi.org/10.1007/s42976-020-00061-w.

75. Alqudah AM, Sallam A, Baenziger PS, Börner A. GWAS: fast-forwarding gene identification and characterization in temperate cereals: lessons from barley-a review. J Adv Res. 2020b;22:119-35 https://doi.org/10.1016/j.jare.2 019.10.013.

76. Thabet SG, Alomari DZ, Alqudah AM. Exploring natural diversity reveals alleles to enhance antioxidant system in barley under salt stress. Plant Physiol Biochem. 2021:166789-98 https://doi.org/10.1016/j.plaphy.2021. 06.030.

77. Babben S, Schliephake E, Janitza P, Berner T, Keilwagen J, Koch M, et al. Association genetics studies on frost tolerance in wheat (Triticum aestivum L.) reveal new highly conserved amino acid substitutions in CBF-A3, CBFA15, VRN3 and PPD1 genes. BMC Genomics. 2018;19(1) Available from: https://doi.org/10.1186/s12864-018-4795-6.

78. Pinheiro J, Bates D, DebRoy S, Sarkar D, Team RC. Linear and nonlinear mixed effects models. R Package Version. 2015;3(1):111.

79. Wang S, Wong D, Forrest K, Allen A, Chao S, Huang BE, et al. Characterization of polyploid wheat genomic diversity using a high-density 90000 single nucleotide polymorphism array. Plant Biotechnol J. 2014;12(6): 787-96 https://doi.org/10.1111/pbi.12183.

80. VSN-International. GenStat for Windows. 18th ed. Hemel Hempstead: VSN International; 2016. Web page: GenStat.co.uk

81. Wickham H. ggplot2-elegant graphics for data analysis. Cham: Springer International Publishing; 2016.

82. Lipka AE, Tian F, Wang Q, Peiffer J, Li M, Bradbury PJ, et al. GAPIT: genome association and prediction integrated tool. Bioinformatics. 2012;28(18):23979 https://doi.org/10.1093/bioinformatics/bts444.

83. Wang J, Zhang Z. GAPIT Version 3: An Interactive Analytical Tool for Genomic Association and Prediction. preprint. 2018.

84. Bhatta M, Morgounov A, Belamkar V, Wegulo SN, Dababat AA, ErginbasOrakci $\mathrm{G}$, et al. Genome-wide association study for multiple biotic stress resistance in synthetic hexaploid wheat. Int J Mol Sci. 2019;20(15):3667 https://doi.org/10.3390/ijms20153667.

85. Liu X, Huang M, Fan B, Buckler ES, Zhang Z. Iterative usage of fixed and random effect models for powerful and efficient genome-wide association studies. PLoS Genet. 2016;12(2):e1005767 https://doi.org/10.1371/journal. pgen.1005767.

86. Pradhan S, Babar MA, Robbins K, Bai G, Mason RE, Khan J, et al. Understanding the genetic basis of spike fertility to improve grain number, harvest index, and grain yield in wheat under high temperature stress environments. Front Plant Sci. 2019;10:1481 https://doi.org/10.3389/fpls.201 9.01481 .

\section{Publisher's Note}

Springer Nature remains neutral with regard to jurisdictional claims in published maps and institutional affiliations.

\section{Ready to submit your research? Choose BMC and benefit from}

- fast, convenient online submission

- thorough peer review by experienced researchers in your field

- rapid publication on acceptance

- support for research data, including large and complex data types

- gold Open Access which fosters wider collaboration and increased citations

- maximum visibility for your research: over $100 \mathrm{M}$ website views per year

At BMC, research is always in progress.

Learn more biomedcentral.com/submissions 